\title{
Association of Position Played and Career Duration and Chronic Traumatic Encephalopathy at Autopsy in Elite Football and Hockey Players
}

Nicole Schwab, MSc, Richard Wennberg, MD, PhD, Karl Grenier, MD, PhD, Carmela Tartaglia, MD, Charles Tator, MD, PhD, and Lili-Naz Hazrati, MD, PhD, FRCPC

Neurology ${ }^{\circledR}$ 2021;96:e1835-e1843. doi:10.1212/WNL.0000000000011668

\section{Correspondence}

Dr. Hazrati

lili-naz.hazrati@sickkids.ca

\section{Abstract \\ Objective}

To determine whether an association exists between career duration or position played and the presence of chronic traumatic encephalopathy (CTE) at autopsy in a series of elite football and hockey players.

\section{Methods}

This retrospective cohort study analyzed postmortem brains of 35 former football or hockey players (29 professional, 6 university varsity/major junior), with the presence of CTE at autopsy as the primary outcome. Position played (highest level), age at retirement (indicator of lifetime exposure to sport), and hockey fighting/penalization histories (surrogate marker for role/style of play) were collected. A blinded neuropathologic evaluation of each participant was performed, providing an assessment for neurodegenerative diseases including CTE, based on the 2015 National Institute of Neurological Disorders and Stroke/National Institute of Biomedical Imaging and Bioengineeringconsensus paper.

\section{Results}

In total, 17 of 35 former players (48.6\%) showed pathologic evidence of CTE. There was no correlation found between position played and CTE presence, nor between hockey fighting/ penalization histories and CTE, in either the football or hockey groups $(p>0.75$, MannWhitney-Wilcoxon). Similarly, there was no association between age at retirement and CTE presence ( $p>0.5$, Mann-Whitney-Wilcoxon). In 24 of 35 cases (68.6\%), other neuropathologies were present, 13 of 24 (54.2\%) of which were coexistent with CTE.

\section{Conclusion}

In this cohort of 35 former collision sports athletes, no significant associations were found between career duration, position or role played, and CTE presence at autopsy. Although limited by the small and nonrepresentative sample studied, these findings suggest that nonsport factors may be important to understand differing susceptibilities among athletes to CTE.

\footnotetext{
From the Department of Laboratory Medicine and Pathobiology (N.S., K.G.), University of Toronto; Toronto Western Hospital Krembil Brain Institute (R.W., C. Tartaglia, C. Tator), Canadian Concussion Centre; Divisions of Neurology (R.W., C. Tartaglia) and Neurosurgery (C. Tator), University Health Network Toronto Western Hospital; The Hospital for Sick Children (L.-N.H.), Pathology; and Canadian Concussion Centre (L.-N.H.), Toronto, Ontario, Canada.

Go to Neurology.org/N for full disclosures. Funding information and disclosures deemed relevant by the authors, if any, are provided at the end of the article. 


\section{Glossary}

$\mathrm{AD}=$ Alzheimer disease; ARTAG = aging-related tau astrogliopathy; CTE = chronic traumatic encephalopathy; NFL = National Football League; NHL = National Hockey League; $\mathbf{p}$-tau = phospho-tau; TBI $=$ traumatic brain injury; TDP-43 = TAR DNA-binding protein 43.

Mild traumatic brain injury (TBI) is common in collision sports such as American football and ice hockey, ${ }^{1-3}$ sustained through tackling, blocking, and rushing collisions ${ }^{4}$ in football and open-ice or board collisions and fighting ${ }^{5-7}$ in hockey. The National Football League (NFL) reported 224 concussions in $2019,{ }^{4}$ and the National Hockey League (NHL) reported a mean of 71.2 to 74.3 concussions per season between 1997 and 2010, ${ }^{8,9}$ although these are likely underestimates. ${ }^{8,9}$ Whereas some individuals experience transient symptoms, including headache, fatigue, and memory loss, ${ }^{10}$ a considerable proportion of concussed individuals have persistent symptoms lasting months or years after injury, ${ }^{11}$ including depression, anxiety, and a propensity for neurodegenerative diseases. ${ }^{12}$

Head trauma has been associated with the progressive neurodegenerative disease chronic traumatic encephalopathy (CTE) ${ }^{13-15}$ Pathologically, CTE diagnosis requires perivascular accumulation of hyperphosphorylated tau in neurons, astrocytes, and cell processes in the depths of cortical sulci. ${ }^{16}$ Various prevalence rates of CTE have been reported in football and hockey players, ranging from $50 \%{ }^{16}$ to $99 \%{ }^{18,19}$ in football and $80 \%{ }^{20}$ in hockey. In football, the likelihood of sustaining a concussion differs depending on playing position: offensive and defensive linemen experience more frequent concussions but at lower impact forces compared to other positions. $^{21,22}$ In hockey, forwards sustain significantly more concussions than defensemen or goaltenders. ${ }^{8,23}$ It is unclear whether this association extends to the risk of CTE. In addition, longer career duration has been significantly associated with an increased number of reported concussions ${ }^{24}$ and has been suggested to increase the odds of developing CTE in life. ${ }^{18}$ The objective of this study was to assess the association between career duration and position played and the pathologic presence of CTE at autopsy.

\section{Methods}

\section{Participants}

The 35 participants were male former elite-level (defined here as professional or university varsity or Canadian major junior) football or hockey players. Informed consent for study participation and brain autopsy was given by the participants' next of kin. The former players studied were selected from a larger brain bank composed of individuals with premortem histories of mild TBI from diverse etiologies. The selected participants represented all of the former elite football and hockey players. Many of the football players from this brain bank were recruited through the Canadian Football League
Alumni Association, where the next of kin, or players themselves if consenting premortem, consented to brain donation as part of a longitudinal study of long-term effects of sportsrelated concussion. Others were recruited through approaches made to family members of recently deceased players shortly after the time of death (often indicated in media reports). For professional hockey players, cases were similarly recruited by approaching the family shortly after death. For university varsity athletes and Canadian major junior hockey players, families approached us to donate the brain for autopsy and consented to brain donation through the Canadian Concussion Centre's website (uhn.ca/KNC/ Research/Projects/Canadian_Concussion_Centre/Pages/ donate_your_brain.aspx), which is open to the public.

Online databases were used to collect all information on playing career duration, age at retirement from competitive sport, playing position at the highest level, fighting history (hockey players only), and penalty minutes (hockey players only). The most frequently used databases included pro-football-reference.com, cflapedia.com, statscrew.com, justsportsstats.com, profootballarchives.com, cfl.ca, nfl.com, nhl.com, hockeydb.com, hockey-reference.com, and hockeyfights.com. Individual team or university websites were also consulted in certain cases. In addition, next of kin were specifically asked about the nature and severity of TBI exposure, including possible incidences of moderate TBI (e.g., loss of consciousness $>30$ minutes, posttraumatic amnesia $>24$ hours) or severe TBI (e.g., loss of consciousness $>24$ hours, posttraumatic amnesia $>7$ days). The players in this study were all exposed to mild TBI through their respective sport but had no known history of more severe TBI. Cause of death for each individual in this study is not included in order to protect the identity of participants. All of the participants had presented during life with neurologic or neuropsychiatric symptoms ranging from minor mood disorders to severe dementia. The quantitative details of this clinical information are currently being collected and will be addressed in a future publication.

\section{Neuropathologic Diagnoses}

Each brain was fixed in formalin and sampled in accordance with the National Institute on Aging-Alzheimer's Association guidelines for the neuropathologic assessment of Alzheimer disease $(\mathrm{AD})$ and other neurodegenerative diseases, ${ }^{25}$ as was used in the CTE diagnostic consensus article. ${ }^{16}$ Up to 25 sample blocks were taken from each case, including cortical, subcortical, cerebellar, and brainstem regions. These blocks included the 12 regions listed in the CTE diagnostic consensus report as being critical for CTE diagnosis but also 
Table Demographics and Playing History of 35 American Football and Ice Hockey Players, Stratified by the Presence or Absence of CTE Neuropathologic Diagnosis

\begin{tabular}{|c|c|c|}
\hline Characteristic & CTE (\%) $(n=17)$ & No CTE $(\%)(n=18)$ \\
\hline \multicolumn{3}{|l|}{ Sex, n (\%) } \\
\hline Male & $17(100)$ & $18(100)$ \\
\hline Female & $0(0)$ & $0(0)$ \\
\hline Mean age at death (SD), y & $59.9(18.4)$ & $65.22(16.8)$ \\
\hline \multicolumn{3}{|l|}{ Sport, n (\%) } \\
\hline Football $(n=24)$ & $11(64.7)$ & $13(72.2)$ \\
\hline Hockey $(n=11)$ & $6(54.5)$ & $5(45.5)$ \\
\hline \multicolumn{3}{|l|}{ Highest level of play, $n(\%)$} \\
\hline Professional (CFL, NFL, NHL) ( $n=29), n$ (\%) & $14(82.4)$ & $15(83.3)$ \\
\hline University or major junior (hockey) $(n=6)$ & $3(17.6)$ & $3(16.7)$ \\
\hline \multicolumn{3}{|l|}{ Primary position at highest level of play, $n$ (\%) } \\
\hline Running back/quarterback/receiver (football, $n=5$ ) & $3(17.6)$ & $2(11.1)$ \\
\hline Defensive back (football, $n=3$ ) & $1(5.9)$ & $2(11.1)$ \\
\hline Tight end/linebacker (football, $n=6$ ) & $3(17.6)$ & $3(16.7)$ \\
\hline Offensive/defensive line (football, $n=10$ ) & $4(23.5)$ & $6(33.3)$ \\
\hline Forward (hockey, $n=7$ ) & $4(23.5)$ & $3(16.7)$ \\
\hline Defense (hockey, $n=4$ ) & $2(11.8)$ & $2(11.1)$ \\
\hline Mean highest-level career duration (SD), $\mathrm{n}$ seasons & $8.9(3.6)$ & $8.0(3.7)$ \\
\hline Mean age at retirement (SD), y & $31.1(5.1)$ & $29.9(4.2)$ \\
\hline For ice hockey players, mean fights per season per player (SD), n & $7.2(6.6)^{a}$ & $8.0(7.3)$ \\
\hline For ice hockey players, mean penalty minutes per season per player (SD) & $98.5(34.6)$ & $110.0(52.2)$ \\
\hline
\end{tabular}

Abbreviations: CFL = Canadian Football League; CTE = chronic traumatic encephalopathy; NFL = National Football League; NHL = National Hockey League. a Excludes 1 university varsity hockey player (fighting not permitted in league).

included all other areas within the National Institute on Aging-Alzheimer's Association guidelines because these cases underwent general brain autopsy in addition to examination for CTE diagnosis. If no pathology was captured, more samples were taken from CTE-relevant areas, including the frontal lobe (bilateral middle, parasagittal, and orbitofrontal), superior and inferior temporal cortex, peri-Rolandic cortex, mesial cortex, occipital/striatal cortex, and parietal cortex. Subcortical areas were also extensively sampled. This sampling methodology ensures that our CTE diagnostic methods are comparable to those of previously published groups and the official CTE diagnostic criteria. Each sample was processed and embedded in paraffin to make formalin-fixed paraffin-embedded blocks. The formalin-fixed paraffinembedded blocks were then cut with a microtome into 6$\mu \mathrm{m}$ sections and mounted on glass slides.

Each slide was stained for Luxol fast blue and hematoxylineosin, followed by a full neuropathologic assessment with the following antibodies: phospho-tau (p-tau; Ser199, Ser202) (polyclonal rabbit, No. 44-768 G: Thermo Scientific [Waltham, MA], 1:1,000), TAR DNA-binding protein 43 (TDP43; polyclonal rabbit, No. PA5-29949, Thermo Scientific, 1: 500 ), $\beta$-amyloid (monoclonal mouse, Dako [Glostrup, Denmark], M0872, 1:50), and $\alpha$-synuclein (monoclonal rabbit, No. 701085, Thermo Scientific, 1:500). Each case was blindly and independently assessed by both a staff neuropathologist and a neuropathology resident to confirm a final diagnosis for each case at autopsy.

Specifically, the diagnosis of CTE was based on the 2015 consensus study by McKee et al. ${ }^{16}$ with the National Institute of Neurological Disorders and Stroke/National Institute of Biomedical Imaging and Bioengineering, in which the absolute requirement for CTE diagnosis is the presence of $\mathrm{p}$-tau aggregates in neurons, astrocytes, and cell processes around small vessels in the depths of cortical sulci. The supportive microscopic criteria listed in the consensus study include 

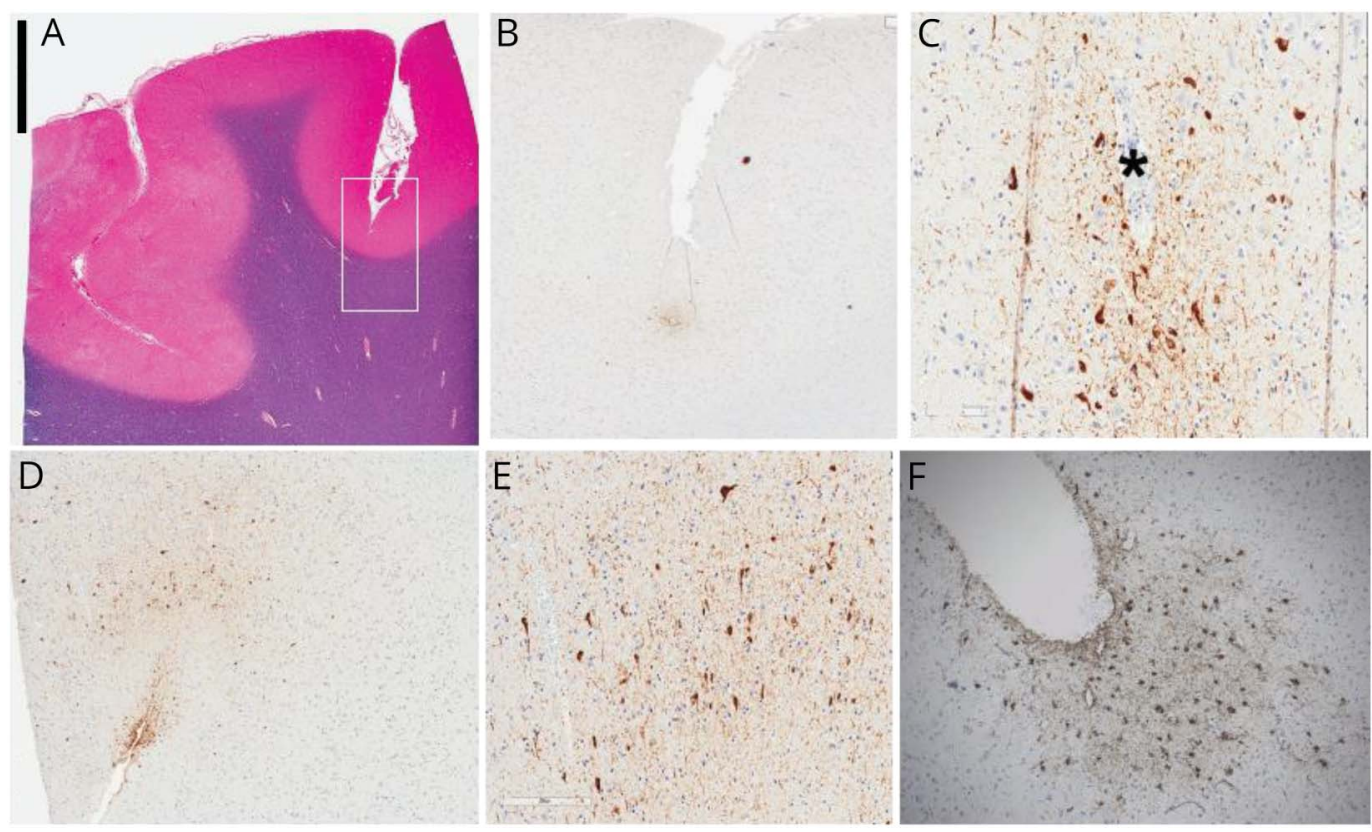

(A) Luxol fast blue and hematoxylin-eosin-stained section from superior frontal gyrus used for phospho-tau (p-tau) distribution study. (B and C) Low- and high-power microscopic photos of 1 depth of sulcus perivascular p-tau deposit. High-power photo (C) shows tau-positive tangles in pyramidal-shaped neurons and positivity in astrocytes (smaller cells) and background neuropil around a vessels ( ${ }^{*}$ ). (D and E) More extensive pathology in the depth of the sulcus and additional subpial tau deposit. (F) Some of the pathologic changes overlap with ARTAG. Scale bar in the top right corner represents $0.5 \mathrm{~cm}$ in panel A; 0.1 $\mathrm{cm}$ in panel $\mathrm{B} ; 0.03 \mathrm{~cm}$ in panels $\mathrm{C}, \mathrm{E}$, and $\mathrm{F}$; and $0.05 \mathrm{~cm}$ in panel $\mathrm{D}$.

p-tau pretangles and neurofibrillary tangles preferentially in superficial cortical layers (II, III) over deep layers (IV, V), in CA2 and CA4 hippocampal regions over CA1 and subiculum, p-tau in subcortical nuclei, p-tau-positive thorny astrocytes in the glial limitans in subpial and periventricular regions, ptau-positive large grain-like or dot-like structures, and TDP43-positive neuronal cytoplasmic inclusions and dot-like structures in the hippocampus, anteromedial temporal cortex, and amygdala. Macroscopic supportive criteria include disproportionate dilation of the third ventricle, septal abnormalities, mammillary body atrophy, and contusions or other signs of previous traumatic injury. ${ }^{16}$ Because these diagnostic criteria do not specify different stages of disease or burdens of pathologic inclusions, we limited our diagnostic assessment to the presence or absence of CTE pathology without quantitatively evaluating the pathologic burden.

\section{Statistical Analysis}

The independent variables in this study were defined as age at retirement, position played (at the highest level), fighting history (expressed as the number of fights per season per player, in the hockey group only), and penalization history (in the hockey group only). For football players, the positions played were subsequently grouped as follows: offensive/ defensive linemen, offensive/defensive backfield/receivers, and tight ends/linebackers. For hockey players, positions were classified as either forward or defense (there were no goaltenders in the study cohort). The dependent variable of this study was defined as the presence of CTE; a secondary outcome measure was the presence of other neuropathology at autopsy.

Statistical analysis was performed with the $\mathrm{R}$ software package (R Foundation for Statistical Computing, Vienna, Austria). Two-sided Mann-Whitney (Wilcoxon rank sum) tests were performed to determine whether cases with CTE-positive and CTE-negative neuropathology differed significantly with respect to age at retirement, playing position, fighting history (hockey group only), and penalization history (hockey group only).

\section{Standard Protocols, Registrations, and Patient Consents}

This study was approved by the Ethics Review Board at the Hospital for Sick Children (REB No. 1000059400). Written informed consent was obtained from all next of kin in this study, and these records are on file.

\section{Data Availability}

Due to the nature of the study and to respect the privacy and identities of individuals in this study, data outside of what are presented in this article are not publicly available.

\section{Results}

\section{Cohort Demographics and Sport History}

This study included a total of 35 male participants, of whom $24(68.6 \%)$ were former football players and $11(31.4 \%)$ were 


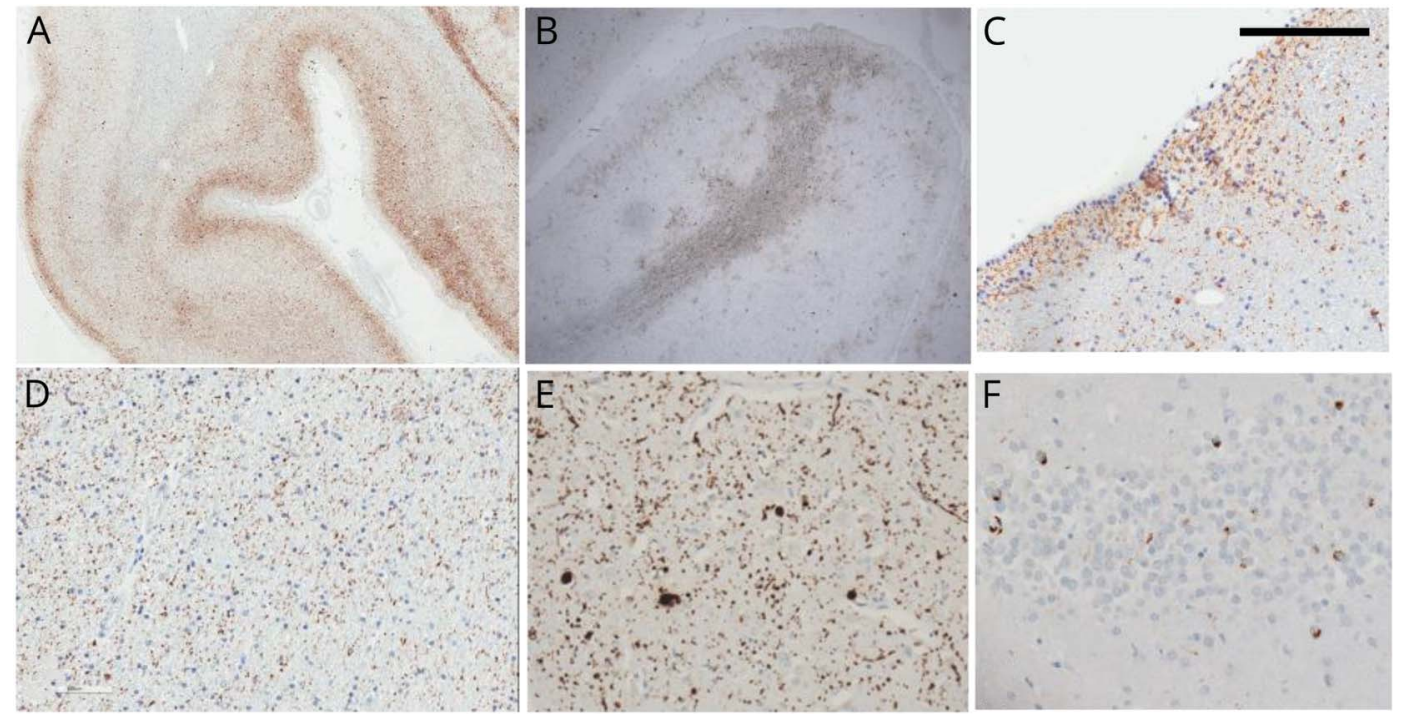

Widespread cortical tau deposits in superficial cortical layers and involving both gyri and sulci in a continuous pattern. Some of the superficial cortical pathology can be focal and involve the crown of the gyri with widespread white matter punctate tau deposits in the (B and D) white matter and (C) subventricular areas. Other concomitant pathologies are a-synuclein deposits in the shape of Lewy bodies and neurites as depicted in the (E) cingulate cortex and (F) TAR DNA-binding protein 43 deposits as shown in the dentate gyrus. Scale bar in the top left corner represents $0.1 \mathrm{~cm}$ in panels A and B and $0.01 \mathrm{~cm}$ in panels C-F.

former hockey players. The mean age at death for all 35 participants was 62.7 years (SD 17.5 years). The mean age at death for football players (68.5 years, SD 14.8 years) was significantly higher than for hockey players (50.0 years, SD 16.9 years $)(p=0.002$, Student $t$ test $)$. Stratified by the presence or absence of CTE at autopsy, the mean age at death was 59.9 years (SD 18.4 years) for those with CTE and 65.22 (SD 16.8 years) for those without CTE. There was no significant difference in age between cases with CTE and without CTE in the overall cohort ( $p=0.38$, Student $t$ test) or when the cohort was stratified by sport (football: 67.5 [SD 14.8] years vs 69.1 [SD 14.9] years, $p=0.80$; hockey: 44.3 [SD 13.1 ] years vs 56.8 [SD 19.8] years, $p=0.27$ ). Twenty-nine of the former players (82.9\%) in this cohort played professionally (Canadian Football League, NFL, or NHL); for 6 players $(17.1 \%)$, the highest level was university varsity or major junior (hockey) (table). Specifics regarding cause of death are not presented, but in general, it can be said that a majority of players in this cohort died of diverse age-related chronic diseases, whereas the younger individuals tended to die unexpectedly of suicide or drug overdose. More detailed clinical information for some of these individuals will be explored in a future publication.

\section{Neuropathologic Diagnosis of CTE}

Within this cohort of former elite football and hockey players, 17 of 35 (48.6\%) were neuropathologically diagnosed with CTE at autopsy. Cases with CTE included 11 of 24 (45.8\%) football players and 6 of 11 (54.5\%) hockey players. Cases with CTE diagnoses were all characterized by the presence of clusters of perivascular p-tau deposits in the cerebral cortex with preferential depth of sulcus distribution in frontoparietal areas. P-tau foci were distributed within neurons and astrocytes, in concordance with the currently accepted criteria for pathologic CTE diagnosis. There was a spectrum of load of pathology. In some cases, the pathology was very focal and scanty and was limited to small perivascular deposits in the depth of sulci (figure 1, A-C). In cases with more widespread pathology, perivascular pathology could be recognized, but additional findings included involvement of superficial cortical layers (figure 2, A and B), subpial and periventricular (figure $2 \mathrm{C}$ ), as well as white matter P-tau deposits (figure 2D). Deep gray matter structures such as nucleus basalis of Meynert, substantia nigra, and locus ceruleus were also variably involved with P-tau tangles. In these cases, other proteinopathies were also frequently encountered and included synucleinopathy (figure 2E), TDP-43 cytoplasmic deposits (figure $2 \mathrm{~F}$ ), and $\beta$-amyloid plaques (not shown). Aging-related tau astrogliopathy (ARTAG) was also frequently noted (figure 1F). Two of the 17 cases of CTE (1 football player, 1 hockey player) had pathologic evidence of diffuse axonal injury; no other gross or histologic pathology indicative of more severe TBI (e.g., hemorrhage, encephalomalacia) was identified.

Other neuropathologic diagnoses were present in $24(68.6 \%)$ individuals in this cohort. These included 15 cases $(62.5 \%)$ of $\mathrm{AD}, 7$ cases $(29.2 \%)$ of athero/arteriolosclerosis, 5 cases (20.1\%) of ARTAG, and 3 cases (12.5\%) of synucleinopathy. Among these 24 cases with other neuropathologic diagnoses, 11 (45.8\%) were coexistent with CTE, whereas 13 (54.2\%) were not coexistent with CTE. 


\section{Position Played Did Not Correlate With CTE Diagnosis at Autopsy}

Among the 24 football players assessed, there were 5 offensive backs/receivers (including running backs, quarterbacks, and receivers), 3 defensive backs, 6 tight ends/linebackers, and 10 offensive/defensive linemen. CTE diagnoses were made in 3 of $5(60 \%)$ offensive backfield/receivers, 1 of $3(33.3 \%)$ defensive backs, 3 of 6 (50\%) tight ends/linebackers, and 4 of 10 (40\%) linemen. There was no significant correlation between the main groups (defined in Methods) of positions played at the highest level and CTE presence at autopsy in football players ( $p>0.75$, Mann-Whitney-Wilcoxon).

Among the 11 ice hockey players, there were 7 forwards and 4 defensemen. CTE diagnoses were made in 4 of 7 (57.1\%) forwards and 2 of 4 (50\%) defensemen. There was no significant correlation between position played at the highest level and CTE presence at autopsy in hockey players ( $p>$ 0.75, Mann-Whitney-Wilcoxon).

\section{Fighting and Penalization Histories in Hockey Did Not Correlate With CTE Diagnosis at Autopsy}

Within the group of 11 hockey players, the mean number of fights per season per player (excluding 1 university varsity player whose highest-level league did not permit fighting) was 7.6 (SD 6.6), and the mean number of penalty minutes per season per player was 103.7 (SD 41.5). Stratified by CTE status, the mean number of fights per season per player at the highest level of play was 7.2 (SD 6.6) for those with CTE pathology and 8.0 (SD 7.3) for those without CTE pathology. Similarly, with respect to penalization histories, stratified by CTE status, the mean number of penalty minutes per season per player was 98.5 (SD 34.6) for those with CTE pathology and 110 (SD 52.2) for those without CTE pathology. Overall, no significant association was found between fighting/ penalization history and CTE presence at autopsy in hockey players ( $p>0.75$, Mann-Whitney-Wilcoxon).

\section{Age at Retirement Did Not Correlate With CTE Diagnosis at Autopsy}

The mean age at retirement within this cohort was 31.1 years (SD 5.1 years). Because elite football or hockey players will have started playing their respective sports competitively at a young age, age at retirement was used as an indicator of overall career duration, that is, lifetime competitive exposure to either hockey or football. In cases with CTE diagnosis at autopsy $(\mathrm{n}=17)$, age at retirement was normally distributed with a skewness of 0.17 and kurtosis of 0.39 . Age at retirement was not associated with CTE diagnosis at autopsy $(p>0.5$, Mann-Whitney-Wilcoxon).

\section{Discussion}

In this study, we found an overall CTE prevalence of $48.6 \%$ in a cohort of former elite-level football and hockey players. The prevalence of CTE in the football group was $45.8 \%$ and in the hockey group was $54.5 \%$. This prevalence is considerably lower than the $84 \%$ to $89 \%$ reported in 2 studies on football players by Mez et al. ${ }^{18,19}$ Other studies concentrating on professional football players have reported CTE prevalence rates from $88 \%$ to $97 \%,{ }^{26,27}$ again much higher than the prevalence found here in a comparable population. Similarly, the prevalence of CTE in former hockey players has been previously reported as up to $80 \%,{ }^{26}$ again much higher than the prevalence rate found in this study. Other studies, however, have estimated a lower prevalence of CTE in former contact and collision sports athletes. ${ }^{28,29}$ Twenty-four of 35 (68.6\%) of the individuals in our cohort had other neuropathologic diagnoses at autopsy, $11(45.8 \%)$ of which were coexistent with CTE.

Our findings add to the variation reported in prevalence of CTE across other studies. It is likely that this variation is due in part to disparities in the criteria for the neuropathologic diagnosis of CTE, which are still preliminary and contain features not specific to CTE. In our opinion, the true prevalence of CTE may be lower than that reported in previous studies. Indeed, some of the pathologic features, in particular deposition of p-tau, listed in the CTE diagnostic criteria are found in other neurodegenerative diseases, including $\mathrm{AD}$ and frontotemporal lobar dementia, which can make it difficult to discern CTE from other comorbid conditions. ${ }^{27}$ CTE is thought to be distinguishable from $\mathrm{AD}$ on the basis of the distribution of $\mathrm{p}$-tau in the depths of cortical sulci and relative absence of $\beta$-amyloid plaques. ${ }^{16}$ However, in a large case series of football players reported by Mez et al, ${ }^{18} \beta$-amyloid was reported in $44.1 \%$ of the diagnosed cases of CTE, a finding contradictory to the currently accepted diagnostic criteria, which both accentuates the overlap between CTE and other neurodegenerative diseases ${ }^{16}$ and calls into question the specificity of the current diagnostic criteria for CTE. The line between a diagnosis of CTE and $\mathrm{AD}$ in former athletes becomes especially blurred with old age because many of these elderly individuals may have features of both diseases. Similarly, it has been suggested that some cases of CTE may simply be misdiagnosed cases of ARTAG, ${ }^{31}$ a neuropathologic condition marked by an age-related accumulation of p-tau in astrocytes, particularly in the subpial, subependymal, and perivascular white and gray matter regions. ${ }^{32}$ These features overlap significantly with the diagnostic criteria for CTE, and a clear distinction between these 2 pathologic findings is controversial. In particular, CTE and ARTAG overlap in their areal distribution in the brain-in the depths of cortical sulci and in subpial and perivascular regions-with the main difference being that ARTAG involves mostly astrocytes whereas CTE involves both neurons and astrocytes. In the absence of taucontaining neurons, astrocytic tau may indicate ARTAG. However, it is important to note that the current diagnostic criteria of CTE are preliminary and may become more specific as guided by future studies. The present study found the diagnosis of other neuropathologies in 11 of 17 (64.7\%) CTE cases, including $\mathrm{AD}$ and ARTAG, further emphasizing this issue in CTE diagnoses 
and supporting the argument that previous reports may have overestimated CTE prevalence.

We did not find an association between age at retirement and the pathologic presence of CTE at autopsy ( $p>0.5$, Mann-WhitneyWilcoxon). This finding is consistent with reports that age at first exposure to football does not correlate with CTE presence or severity. ${ }^{19,22}$ Although age at first exposure and overall career duration are different variables, both a lower age at first exposure and a later age at retirement imply a greater exposure to head trauma over time. This is especially true for a cohort of elite football and hockey players, who would have started playing competitively at a similar early age (particularly in the case of hockey). Although we found no association in our study, Mez et al. ${ }^{19}$ recently reported a direct correlation between duration of football play and CTE. Perhaps relatedly, Alosco et al. $^{33}$ have suggested that although a younger age at exposure is not associated with severity of CTE pathology, it may reduce an individual's resiliency to late-life neuropathology in general. However, there is currently no evidence to support this hypothesis.

We also found no association between primary playing position or, in hockey, the role played (i.e., fighting history [e.g., "enforcer" role] or general roughness [with penalty minutes serving as a surrogate measure of a rough, more collision-prone style of play]) and the pathologic presence of CTE at autopsy ( $p>0.75$, Mann-Whitney-Wilcoxon). These findings are particularly interesting because several studies have reported significantly different rates of concussions when stratified by playing position. In 2016, Yengo-Kahn et al. ${ }^{34}$ reported that the greatest concussion rates in football players were found in quarterbacks and linebackers. In contrast, Baugh et al. $^{35}$ reported that offensive linemen had the highest number of undiagnosed concussions and more frequent postimpact symptoms and suggested that positions in which players experience low-intensity but frequent impacts present a higher risk for concussions. Clinically, no significant difference was found in suicide mortality rate between football players of different playing positions. ${ }^{36}$ Although studies suggest significant differences in concussion rates between playing positions, the relationship between positions and the pathologic presence of CTE remains unclear. In the 2 series of football players reported by $\mathrm{Mez}$ et al., ${ }^{18,19}$ information about playing positions for each athlete was assessed, but no significant interactions were reported between position and CTE pathology. No studies to date have assessed the relationship between CTE pathology and position played in hockey. However, it has been shown that forwards sustain significantly more concussions than other playing positions. , $^{83}$

Whether impact frequency or impact severity is a more important risk factor for CTE is an unresolved question. Certain collision sport playing positions, for example, quarterback or wide receiver in football, are more subject to low-frequency, yet high-severity, impacts. The same may also be true for forwards in hockey. ${ }^{8}$ In contrast, other playing positions such as football linemen might experience numerous, frequent impacts but at lower impact velocities. Nonetheless, this study and other published case series ${ }^{18,19}$ did not find significantly different rates of CTE associated with playing position. This discrepancy highlights the complexity of the relationship between reported number, or even severity, of concussions and CTE presence at autopsy. It may be the case that a low number of high-velocity impacts is equivalent to a high number of lowvelocity impacts with respect to the potential to cause CTE later in life. If this is the case, then the number of reported concussions, as is often used as an independent variable in case series, may not be a reliable indicator of CTE risk.

It is important to acknowledge the limitations posed by our relatively small sample size and the possibility that the failure to identify associations between playing position and CTE diagnosis might represent false-negative, type II errors. For example, to detect a $50 \%$ difference in CTE diagnosis between groups with $80 \%$ power, a sample size of $\approx 14$ is needed, a target not quite met by some of our comparative analyses. Detection of smaller differences in risk would of course require even more subjects; thus, future studies including more individuals and ultimately meta-analyses will be needed to address these limitations. Another limitation of our study, mentioned here for completeness, pertains to a heterogeneity within the group of professional hockey players; specifically, protective helmet use was not mandatory for players entering the NHL until 1979, and 4 of the 8 former NHL players in our cohort played without head protection for at least part of their NHL careers ( 1 of these 4 players was diagnosed with CTE at autopsy).

It should also be acknowledged that our methods could not entirely exclude the possibility that 1 or more of the former elite athletes in this group may have suffered a head injury more severe than concussion. Although next of kin were specifically asked about the historical occurrence of signs diagnostic of moderate or severe TBI, a validated TBI screening tool was not used for this questioning. Indeed, 2 individuals did show diffuse axonal injury pathology, compatible with moderate to severe TBI, and both individuals had a CTE diagnosis. Nonetheless, more definitive pathologic evidence of moderate-severe TBI (e.g., hemorrhage, encephalomalacia) was not found in any of the cases, with or without a CTE diagnosis.

Another important caveat to the present study is the absence of a control group of individuals who played elite-level football or hockey but who did not have any neurologic symptoms in life. Patients and next of kin are significantly more likely to participate in brain donation programs if they are already concerned that they have the disease being studied. ${ }^{37}$ This referral bias is inherently present in every retrospective CTE study, including the present study, and thus the current data are relevant predominantly to the population of elite-level athletes who have experienced neurologic symptoms, ranging from mood disorders to dementia or movement disorders.

The limitations of a small and nonrepresentative sample notwithstanding, the findings of this study suggest that other factors not assessed in the present study, outside of sport exposure 
and playing position, might contribute in an important way to an individual athlete's susceptibility to CTE. Elite collision sport athletes may differ from the general population in many ways besides exposure to repetitive head trauma, including strenuous exercise routines, body habitus, the use of ergogenic or recreational drugs, and other personal and sociological factors. Indeed, genetic predispositions, alcohol and drug use, stress, or systemic comorbid conditions may significantly affect an individual's propensity for-or relative protection fromthe development of CTE later in life.

\section{Study Funding}

Study funded by donations through the Canadian Concussion Centre at the Toronto Western Hospital.

\section{Disclosure}

L.-H. Hazrati acknowledges research funding from the Canadian Institutes of Health Research and the National Institute of Neurological Disorders and Stroke. She has served pro-bono as a consultant and expert witness in the area of neurotrauma and neuropathology. The other authors report no disclosures relevant to the manuscript. Go to Neurology.org/ $\mathrm{N}$ for full disclosures.

\section{Publication History}

Received by Neurology August 4, 2020. Accepted in final form December 29, 2020.

\section{Appendix Authors}

\begin{tabular}{|c|c|c|}
\hline Name & Location & Contribution \\
\hline $\begin{array}{l}\text { Nicole } \\
\text { Schwab, } \\
\text { MSc }\end{array}$ & $\begin{array}{l}\text { University of Toronto, } \\
\text { Ontario, Canada }\end{array}$ & $\begin{array}{l}\text { Roles in data acquisition, } \\
\text { drafting the initial } \\
\text { manuscript, and finalizing } \\
\text { manuscript with all authors' } \\
\text { input }\end{array}$ \\
\hline
\end{tabular}

\begin{tabular}{lll}
\hline $\begin{array}{l}\text { Richard } \\
\text { Wennberg, } \\
\text { MD, PhD }\end{array}$ & $\begin{array}{l}\text { Toronto Western } \\
\text { Hospital, Ontario, } \\
\text { Canada }\end{array}$ & $\begin{array}{l}\text { Role in data analysis } \\
\text { (statistical analyses) and } \\
\text { finalizing the manuscript }\end{array}$ \\
\hline $\begin{array}{l}\text { Karl } \\
\text { Grenier, } \\
\text { MD, PhD }\end{array}$ & $\begin{array}{l}\text { McGill University, } \\
\text { Contreal, Quebec, }\end{array}$ & $\begin{array}{l}\text { Neuropathologic diagnoses } \\
\text { of all cases }\end{array}$ \\
\hline $\begin{array}{l}\text { Carmela } \\
\text { Tartaglia, } \\
\text { MD, PhD }\end{array}$ & $\begin{array}{l}\text { Toronto Western } \\
\text { Hospital, Ontario, }\end{array}$ & $\begin{array}{l}\text { Role in finalizing the } \\
\text { manuscript, and a key } \\
\text { member of the Canadian } \\
\text { Concussion Centre in which } \\
\text { this research was produced }\end{array}$ \\
& &
\end{tabular}

\begin{tabular}{lll}
\hline Charles & Toronto Western & Role in finalizing the \\
Tator, MD, & Hospital, Ontario, & manuscript, and the leader of \\
PhD & Canada & the Canadian Concussion \\
& Centre in which this research \\
& was produced
\end{tabular}

\begin{tabular}{ll}
\hline Lili-Naz & The Hospital for Sick \\
Hazrati, MD, & Children, Toronto,
\end{tabular}

PhD $\quad$ Ontario, Canada

\section{References}

1. Gardner AJ, Quarrie KL, Iverson GL. The epidemiology of sports-related concussion: what the rehabilitation clinician needs to know. J Orthop Sports Phys Ther 2019;49: 768-778.

2. Wennberg RA, Tator CH. National Hockey League reported concussions $1986-87$ to 2001-02. Can J Neurol Sci 2003;30:206-209.

3. Casson IR, Viano DC, Powell JW, Pellman EJ. Twelve years of National Football League concussion data. Sports Health 2010;2:471-483.

4. Battista J NFL Reveals 2019 Injury Data, Hopeful Rule Changes Are Working. NFL. Available at: nfl.com/news/story/0ap3000001098679/article/nfl-reveals-2019-injury-data-hopeful-rule-changes-are-working. Accessed April 30, 2020.

5. Wennberg R. Collision frequency in elite hockey on North American versus international size rinks. Can J Neurol Sci 2004;31:373-377.

6. Wennberg R. Effect of ice surface size on collision rates and head impacts at the World Junior Hockey Championships, 2002 to 2004. Clin J Sport Med 2005;15:67-72.

7. Anderson GR, Melugin HP, Stuart MJ. Epidemiology of injuries in ice hockey. Sports Health 2019;11:514-519.

8. Wennberg RA, Tator CH. Concussion incidence and time lost from play in the NHL during the past ten years. Can J Neurol Sci 2008;35:647-651.

9. Hutchinson MG, Comper P, Meeuwisse WH, Echemendia RJ. An observational method to code concussions in the National Hockey League (NHL): the heads-up checklist. Br J Sports Med 2014;48:125-129.

10. Polinder S, Cnossen MC, Real RGL, et al. A multidimensional approach to postconcussion symptoms in mild trauma brain injury. Front Neurol 2018;9:1113.

11. Hiploylee C, Dufort PA, Davis HS, et al. Longitudinal study of postconcussion syndrome: not everyone recovers. J Neurotrauma 2017;34:1511-1523.

12. Dean PJ, Sterr A. Long-term effects of mild traumatic brain injury on cognitive performance. Front Hum Neurosci 2013;7:30.

13. Stein TD, Alvarez VE, McKee AC. Concussion in chronic traumatic encephalopathy. Curr Pain Headache Rep 2015;19:47.

14. Safinia C, Bershad EM, Clark HB, et al. Chronic traumatic encephalopathy in athletes involved with high-impact sports. J Vasc Interv Neurol 2016;9:34-48.

15. Johnson VE, Stewart W, Arena JD, Smith DH. Traumatic brain injury as a trigger of neurodegeneration. Adv Neurobiol 2017;15:383-400.

16. McKee AC, Cairns NJ, Dickson DW, et al. The first NINDS/NIBIB consensus meeting to define neuropathological criteria for the diagnosis of chronic traumatic encephalopathy. Acta Neuropathol 2016;13:75-86.

17. Hazrati LN, Tartaglia MC, Diamandis $P$, et al. Absence of chronic traumatic en cephalopathy in retired football players with multiple concussions and neurological symptomatology. Front Hum Neurosci 2013;7:222.

18. Mez J, Daneshvar DH, Kiernan PT, et al. Clinicopathological evaluation of chronic traumatic encephalopathy in players of American football. JAMA 2017;318:360-370.

19. Mez J, Daneshvar DH, Abdolmohammadi B, et al. Duration of American football play and chronic traumatic encephalopathy. Ann Neurol 2020;87:116-131.

20. McKee AC, Stern RA, Nowinski CJ, et al. The spectrum of disease in chronic traumatic encephalopathy. Brain 2013;136:43-64.

21. Schnebel B, Gwin JT, Anderson S, Gatlin R. In vivo study of head impacts in football: a comparison of National Collegiate Athletic Association Division I versus high school impacts. Neurosurgery 2007;60:490-495.

22. Broglio SP, Sosnoff JJ, Shin S, He X, Alcaraz C, Zimmerman J. Head impacts during high school football: a biomechanical assessment. J Athl Train 2009;44:342-349.

23. Benson BW, Meeuwisse WH, Rizos J, Kang J, Burke CJ. A prospective study of concussions among National Hockey League players during regular season games: the NHL-NHLPA Concussion Program. CMAJ 2011;183:905-911.

24. Clark MD, Varangis EML, Champagne AA, et al. Effects of career duration, concussion history, and playing position on white matter microstructure and functional neural recruitment in former college and professional football athletes. Radiology 2018;286:967-977.

25. Hyman BT, Phelps CH, Beach TG, et al. National Institute on Aging-Alzheimer's Association guidelines for the neuropathologic assessment of Alzheimer's disease. Alzheimers Dement 2012;8:1-13.

26. Iverson GL, Gardner AJ, Shultz SR, et al. Chronic traumatic encephalopathy neuropathology might not be inexorably progressive or unique to repetitive neurotrauma. Brain 2019;142:3672-3693.

27. Schwab N, Hazrati LN. Assessing the limitations and biases in the current understanding of chronic traumatic encephalopathy. J Alzheimers Dis 2018;64: 1067-1076.

28. Omalu B, Bailes J, Hamilton RL, et al. Emerging histomorphologic phenotypes of chronic traumatic encephalopathy in American athletes. Neurosurgery 2011;69: 173-183.

29. Finkel AM, Bieniek KF. A quantitative risk assessment for chronic traumatic encephalopathy (CTE) in football: how public health science evaluates evidence. Hum Ecol Risk Assess Int J 2019;25:564-589.

30. Binney ZO, Bachynski KE. Estimating the prevalence at death of CTE neuropathology among professional football players. Neurology 2019;92:43-45.

31. Iverson GL, Keene CD, Perry G, Castellani RJ. The need to separate chronic traumatic encephalopathy neuropathology from clinical features. J Alzheimers Dis 2018; $61: 17-28$.

32. Kovacs GG, Ferrer I, Grinberg LT, et al. Aging-related tau astrogliopathy (ARTAG): harmonized evaluation strategy. Acta Neuropathol 2016;131:87-102.

33. Alosco ML, Mez J, Tripodis Y, et al. Age of first exposure to tackle football and chronic traumatic encephalopathy. Ann Neurol 2018;83:886-901. 
34. Yengo-Kahn AM, Johnson D, Zuckerman SL, Solomon GS. Concussions in the National Football League: a current concepts review. Am J Sports Med 2016;44:801-811.

35. Baugh CM, Kiernan PT, Kroshus E, et al. Frequency of head-impact-related outcomes by position in NCAA Division I collegiate football players. J Neurotrauma 2015;32: 314-326.
37. EJ, Hein MJ, Gersic CM. Suicide mortality among retired National Football League players who played 5 or more seasons. Am J Sports Med 2016;44:2486-2491. Maroon JC, Winkelman R, Bost J, Amos A, Mathyssek C, Miele V. Chronic traumatic encephalopathy in contact sports: a systematic review of all reported pathological cases. PLoS One 2015; 10:e0117338. 


\section{Neurology}

\section{Association of Position Played and Career Duration and Chronic Traumatic Encephalopathy at Autopsy in Elite Football and Hockey Players \\ Nicole Schwab, Richard Wennberg, Karl Grenier, et al. \\ Neurology 2021;96;e1835-e1843 Published Online before print February 24, 2021 \\ DOI 10.1212/WNL.0000000000011668}

This information is current as of February 24, 2021

\section{Updated Information \&} Services

References

Citations

Permissions \& Licensing

Reprints including high resolution figures, can be found at: http://n.neurology.org/content/96/14/e1835.full

This article cites 36 articles, 3 of which you can access for free at: http://n.neurology.org/content/96/14/e1835.full\#ref-list-1

This article has been cited by 6 HighWire-hosted articles: http://n.neurology.org/content/96/14/e1835.full\#\#otherarticles

Information about reproducing this article in parts (figures,tables) or in its entirety can be found online at:

http://www.neurology.org/about/about_the_journal\#permissions

Information about ordering reprints can be found online:

http://n.neurology.org/subscribers/advertise

Neurology ${ }^{\circledR}$ is the official journal of the American Academy of Neurology. Published continuously since 1951, it is now a weekly with 48 issues per year. Copyright Copyright ( 2021 The Author(s). Published by Wolters Kluwer Health, Inc. on behalf of the American Academy of Neurology.. All rights reserved. Print ISSN: 0028-3878. Online ISSN: 1526-632X.

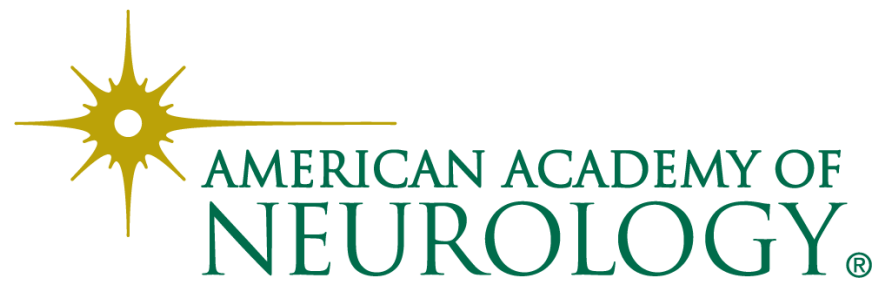

